\title{
Influencia de la cultura empresarial en el éxito o fracaso de los talleres de hamacas y de calzado de cuero para mujer de la ciudad de Masaya
}

Darling E. Rojas Mendoza ${ }^{1}$, Karla P. Escobar Mayorga ${ }^{1}$, Eusebia M. Corea Quintana ${ }^{1}$, Luisa Amanda Avilés ${ }^{1}$

1 Maestría en Administración y Dirección de Empresas (MADE) Facultad de Ciencias Económicas y Empresariales de la UCA. Apdo. 69, Managua, Nicaragua.

Recibido: abril 2006 / Aceptado: mayo 2006

ESTE TRABAJO EXPLORA LAS OPORTUNIDADES Y OBSTACULOS que enfrentan dos sectores productivos de la ciudad de Masaya, la artesanía de hamacas y el calzado de cuero para mujeres, a partir de su cultura empresarial. Los éxitos y los fracasos de uno y otro sector se explican y fundamentan en el estilo empresarial característico de los talleres productores. Para realizar la investigación, se eligieron 15 talleres de cada especialidad y se estudió la cultura empresarial y el estilo de dirección. Este enfoque empresarial raramente se ha aplicado a los estudios de las diferentes empresas nicaragüenses y menos aún, de los talleres artesanales. Con este trabajo se espera abrir un ámbito a la exploración y la investigación.

Palabras clave: cultura corporativa, talleres-producción y dirección investigaciones, calzado-industria y comercio, hamacas-industria y comercio

\section{Introducción}

La influencia de la cultura empresarial para el éxito o el fracaso en los talleres artesanales es un aspecto que todavía no se ha investigado en Nicaragua. En este caso, se estudia esta cultura en los talleres de hamacas y calzado de cuero para mujer de la ciudad de Masaya. Se pretende conocer la percepción ${ }^{1}$ del mundo y de su entorno de los líderes de los talleres más representativos; captar los valores, creencias, tradiciones y políticas gerenciales que han influido en la actividad productiva; y reconstruir el valor de la cultura 
empresarial en la búsqueda de apoyo sectorial y gubernamental para el sector, con miras a facilitar oportunidades de desarrollo y de mercado.

El estudio tiene como población objetivo a todos los talleres de artesanos de hamaca y calzado de cuero para mujer de la ciudad de Masaya. La muestra se definió por un total de 15 talleres por cada sector, para un total de 30. Se trabajó sobre la hipótesis de que los talleres han tenido influencia de la cultura empresarial sobre el éxito o fracaso de su actividad productiva comercial a lo largo de su historia.

Pero la cultura no es un valor tangible, sino que está implícito en el funcionamiento de la empresa. Por ello, se investigaron las manifestaciones de esa cultura en las expresiones y actuaciones de la empresa artesanal: concepto del mundo, personalidad de los líderes y miembros, rituales y símbolos, sistemas de información y comunicación, estrategias y políticas empresariales, marketing, condiciones económicas y tecnológicas, estructura organizativa y legal, manejo de los recursos humanos, valores, cadena de abastecimiento de insumos, visualización del rol del estado para el sector, incorporación a mercados externos, etc.

\section{EI sello ecológico}

El sello ecológico ${ }^{2}$ es la primera iniciativa centroamericana para identificar y diferenciar productos menos dañinos al ambiente, mejorar su competitividad en el mercado interno y consolidarlos en el mercado internacional. Para asegurar la credibilidad del sello ecológico, el sistema está montado en certificadores, verificadores y pruebas de laboratorio acreditados según normas nacionales basadas sobre normas internaciones como las de la Organización de Normalización Internacional (ISO), que es un sistema imparcial. El logotipo del sello ecológico es una marca registrada y protegida por la ley. El sistema tiene sus bases en el Decreto Ejecutivo 71-99 de creación del sello ecológico de Nicaragua. Este decreto ha sido avalado por el Ministerio de Fomento, Industria y Comercio (MIFIC).

\section{La hamaca}

La hamaca es un producto no perecedero, fabricada a base de manila (hilo retorcido), madera y objetos de aluminio. Se producen con poco equipamiento industrial: motor, rueda de madera y cocina de gas. Los talleres más organizados importan la materia prima (manila y tintes certificados); el resto los compran a intermediarios locales.

La hamaca se ubica en el sector industrial de la manufactura de textil, pero carece de algunos eslabones estratégicos de la cadena productiva. Antiguamente, las hamacas se fabricaron con fibras vegetales como la cabuya y la pita pero, a consecuencia del auge algodonero de los años cincuenta, se sustituyeron por el algodón, que es una materia prima más versátil y representa el 67\% de los costos de producción ${ }^{3}$, pues sólo el 15\% se destina a pago de mano de obra. Pero Nicaragua ya no produce algodón por lo que se ha intentado sustituirlo con materiales sintéticos, pero no ha dado resultado.

Las hamacas tienen un mercado interno cuyos intermediarios obtienen grandes utilidades 
adquiriendo por volumen y revendiendo a buenos precios. Pero también hay un interesante mercado internacional que se ha ampliado con los Tratados de Libre Comercio (TLC) de Nicaragua con México y con Estados Unidos, pues la hamaca es un producto que puede introducirse en ambos países sin pago de aranceles ni restricciones en cantidad. Además, el Sistema Generalizado de Preferencia (SGP) permite a Nicaragua exportar productos de origen nicaragüense con preferencias arancelarias a Canadá, Unión Europea, y Japón. Asimismo, la Unión Aduanera con Guatemala y El Salvador, que entró en vigencia el Primero de Enero de 2003 y el Mercado Común Centroamericano ha eliminado la mayoría de los obstáculos al comercio intraregional, especialmente a las materias primas, bienes de capital y bienes finales.

\section{Las hamacas de Masaya}

La hamaca es un producto ecológico y manufacturado, con alta demanda, especialmente entre capas económicas medias y altas de los países desarrollados. Hay organizaciones que manejan el concepto de comercio justo ${ }^{4}$, que consiste en pagar el precio justo al productor para elevar su nivel de vida. En Nicaragua, la Organización de las Naciones Unidades para el Desarrollo Industrial (ONUDI) es el organismo que implementa este concepto. La exportación de hamacas de 2003 casi duplicó la de 2002., pero el Plan Nacional de Desarrollo (PND) vigente no contempla apoyar al sector.

En consecuencia, los productores no acceden a financiamiento por la falta de políticas gubernamentales; tienen poco apoyo de organismos no gubernamentales; los productores son pobres y, por ello, no son sujeto de crédito; y las tasas de interés son altas, lo que dificulta el desarrollo de los talleres. Además, el individualismo y la baja capacitación académica obstaculizan la organización gremial.

En el aspecto legislativo, la ley 382, publicada en La Gaceta 70, el 16 de abril del 2001, de admisión temporal para perfeccionamiento activo y facilitación de las exportaciones, permite el ingreso de mercancías sin pago de derechos, impuestos de importación, u otros atributos, si son sometidas a alguna operación posterior en el país. Por lo tanto, los insumos para la elaboración de hamacas están exonerados de impuestos de introducción.

\section{Análisis de las fuerzas competitivas}

El 88\% de los talleres son muy pequeños pero producen mensualmente el 28\% del total. Aunque el producto no es de calidad, compite por precio pero sin estrategias de promoción. No tienen inversión infraestructura, maquinaria, materiales, u otro aspecto que los comprometa a permanecer en el sector. Los otros talleres están más organizados, participan con el 72\% mensual del producto, producen hamacas de media y buena calidad, tienen altos costos para salir del negocio, y sus estrategias de promoción, producto y producción son mínimas.

El sector de hamacas de la ciudad de Masaya es actualmente un sector atractivo, con buenas oportunidades de crecimiento internacional por la calidad del producto, el nivel actual de las fuerzas competitivas, la desregulación comercial actual y la apertura comercial con la firma 
de los tratados de libre comercio de Nicaragua con México y Estados Unidos de América.

\section{Sistema de valor de la artesanía de hamacas}

En el sistema de valor interactúan tres actores: proveedores, productores y comercializadores ${ }^{5}$. Los proveedores facilitan los insumos: hilo, tintes, guarda cabos, bolillos y maquinaria artesanal. En el mercado local hay tres productores de manila que venden en cantidades mayores a las 300 libras, aunque con baja calidad. Los talleres calificados como microempresas importan tintes desde El Salvador y México. Los guardacabos se compran en ferreterías de Granada, Managua y Masaya, a precios módicos. Los bolillos se compran a talleres de carpintería, de baja calidad porque la madera no es la adecuada. La maquinaria es muy sencilla y se adquiere en el país. Sólo el Taller Hamacas Esperanza realiza el 90\% del proceso productivo total, siendo 10\% restante las partes de madera, que se elaboran en talleres locales de Masaya. Cuando este taller realice el 100\% de su proceso productivo, estará listo para contar con el sello ecológico, con el cual adquirirá otra ventaja competitiva.

Los talleres que exportan son: ${ }^{6}$ Hamacas Esperanza, José Ramiro Suazo, Wilfredo Suazo, Oscar Suazo, Marvin Suazo, Félix Suazo, Elmer Suazo, Agustín Sánchez y fábrica de Hamacas la Siesta; y las Cooperativas de COOPHAMACA y ADEPRESMA. Este grupo ha logrado abrir espacio en Europa (Alemania, Italia y Francia), Estados Unidos (Houston, Miami, Carolina del Sur y Norte), América del Sur (Argentina y Chile) y Centroamérica.

\section{Cultura empresarial en la artesanía de hamacas}

En la cultura empresarial interactúan tres componentes: el recurso humano, la estructura y los procesos de la organización. El proceso de interacción de estos componentes genera conductas que reflejan las actitudes, creencias, costumbres y valores dominantes y compartidos.

Para conocer la cultura empresarial en los talleres de hamacas de Masaya, se hicieron 15 entrevistas, de las cuales, nueve al dueño, una al administrador y cinco a los trabajadores y a una cooperativa. Todos los talleres participantes están inscritos en la Alcaldía, el $40 \%$ lleva registros contables y el $20 \%$ son micro, con menos de cinco trabajadores. La propiedad es mayoritariamente individual, con una estructura organizativa simple: el jefe y sus trabajadores; no hay manual de funciones, las orientaciones se dan verbalmente y pocas veces, porque el jefe supone que sus trabajadores saben lo que tienen que hacer. La educación de jefes y trabajadores es baja y el lenguaje, pobre.

La cooperativa entrevistada tiene una estructura organizativa diferente: hay una junta directiva compuesta por los propios miembros, un administrador que coordina todas las actividades operativas y financieras y un contador que lleva los registros contables de la cooperativa, que cuenta con un manual de funciones para el personal fijo y de planta.

Respecto a la infraestructura, maquinaria y ubicación del taller, en todos los talleres se trabaja en la casa de habitación del dueño, se utiliza maquinaria artesanal y la infraestructura en la 
mayoría no es buena, es decir no es adecuada. Sólo la Cooperativa cuenta con instalaciones propias y adecuadas.

\section{Carencias}

Los talleres no han definido misión, visión y objetivos, porque no los consideran necesarios. La cultura de liderazgo rígido dificulta los valores de eficiencia organizacional como: sentido de pertenencia, trabajo en grupo y liderzazo participativo. Los canales de comunicación son débiles y se funciona en base a canales informales (rumores). Los problemas se resuelven dejando que el jefe se encargue de resolverlo todo. La capacitación ofrecida por instituciones no gubernamentales no es aprovechada en su totalidad por todos los talleres. Los que sí las han aprovechado, han mejorado la comercialización, la atención al cliente, la preparación de tintes ecológicos, etc.

En síntesis, la mayoría de los talleres entrevistados carecen de coordinación en el funcionamiento de la estructura organizativa; carecen de un sistema de control de calidad; tienen un sistema de gestión de recursos humanos que no compromete a los trabajadores porque la estrategia de atención al ser humano no está definida y el sistema de selección del personal es ineficiente; y el sistema logístico y de comercialización funciona de forma limitada

Hay un conjunto de creencias positivas, compartidas por jefes y trabajadores, que forman parte de la cultura actual y de la deseada. Se trata al individuo como integrante de un equipo que aporta sus capacidades al logro del objetivo del dueño del taller. Las órdenes fluyen por la cadena de mando, de arriba hacia abajo. Se produce sin conciencia de que es necesario vender.

\section{Entre el éxito y el fracaso}

Los elementos de la cultura empresarial que han incidido en el éxito de algunos talleres de hamacas de la ciudad de Masaya, son: autonomía individual de los trabajadores; estructura administrativa, normas, procedimientos y reglas concretas; apoyo de los jefes de los talleres a sus subordinados y entre los trabajadores; identificación de los miembros con los valores del taller; recompensa al desempeño; tolerancia y manejo del conflicto; capacidad para interactuar fluidamente con el resto de los miembros del taller y con los clientes; comunicación; adaptación ante el cambio; capacitación; espíritu emprendedor, con visión a largo plazo; objetivos claros; mantenimiento de valores, creencias, símbolos, tradiciones heredados por los antepasados y compartidos con los miembros del taller; disponibilidad positiva de los miembros del taller para realizar trabajos creativos y de calidad, a fin de destacarse en el taller y ante la competencia, lo que logra satisfacer sus aspiraciones propias y contribuir a la efectividad productiva del taller.

Los elementos de la cultura empresarial que han incidido en el fracaso de la mayoría de los talleres de hamacas de la ciudad de Masaya, son: ausencia de misión, visión, objetivos y planes de acción; reglas y valores que no se transmiten en el taller; desconfianza vertical y horizontal; comunicación informal (rumores); los trabajadores son familiares y conocidos, 
por lo que no cuestionan los razonamientos del jefe aunque estén errados; ausencia de programas de capacitación; resistencia al cambio.

\section{Búsqueda de soluciones}

Para generar componentes clave de la cultura empresarial, se sugiere: elaborar un programa de desarrollo cultural fundamentado en los principios y valores del taller; creencias, mitos, comunicación y liderazgo determinando la coherencia de estos factores con los principios y valores establecidos por el taller; y políticas que involucren al personal en la cultura del taller.

Para desarrollar la cultura se recomienda: capacitar sobre cultura empresarial a todos los miembros del taller para que conozcan su importancia para el éxito; fortalecer constantemente la cultura empresarial; reafirmar los valores y demás elementos valiosos de la cultura actual y cambiar los que sean disfuncionales; hacer que los jefes sean modelos positivos; seleccionar, promover y apoyar a los trabajadores que abrazan los valores del taller; crear y aplicar un sistema de premios para favorecer la aceptación de los valores del taller; reemplazar las normas no escritas con reglas formales de obligado cumplimiento; evaluar los resultados obtenidos por los diagnósticos y dar un nuevo direccionamiento interno al taller, en búsqueda del éxito.

Además, el gobierno debería apoyar al sector, por medio de la alcaldía de Masaya y la participación de las Universidades, para fortalecer la cultura empresarial de los talleres.

\section{Sector productor de calzado de cuero para mujer}

Los talleres de calzado para mujer se concentran en Masaya y se especializan por tipo de zapato, predominando el estilo sandalia. La cadena productiva no integra fases estratégicas desde la crianza del ganado vacuno, la transformación de las pieles en cuero por las tenerías y la comercialización dirigida al consumidor final nacional y extranjero.

El sector tiene un gran potencial económico y es fuerte generador de empleo porque el calzado tiene gran demanda y atractivo. Genera alto valor agregado porque utiliza gran porcentaje de materia prima nacional y mano de obra local, pero no cuenta con la inversión y el financiamiento necesarios para su crecimiento y desarrollo, ni con políticas económicas, financieras organizativas y sociales que contribuyan a su desarrollo. Los intermediarios encarecen el precio de los insumos y, por lo tanto, del producto. Los insumos importados para la elaboración del cuero se utilizan directamente, por lo que pagan impuestos de introducción.

En Masaya, predominan los pequeños artesanos. En la década delos 80, el sector fuefavorecido con la promulgación de la Ley Provisional para Estímulo, Rehabilitación y Protección de la Pequeña Industria Artesanal, que establecía beneficios fiscales para el sector: exoneración de impuestos sobre la renta y para importación de maquinarias y equipos. Pero desde los 90 , las políticas gubernamentales obstaculizaron su desarrollo. 
Actualmente, el 90\% de la producción se elabora a partir de cuero sintético. El 10\% restante utiliza el cuero natural de vaca de mediana calidad, adquirido en el mercado nacional, pero las tenerías exportan el cuero de primera calidad, dejando la materia prima inferior a los artesanos locales. Los productores no tienen instrumentos legales, económicos y financieros para revertir esta situación. El PND no contempla políticas gubernamentales para desarrollar el sector.

En consecuencia, el sector está sumido en la depresión económica. Además, los artesanos son muy individualistas, aunque buen número de propietarios de talleres están tratando de organizarse en la Asociación de Productores de la Industria del Calzado de Masaya (ASOPICMA), en proceso de legalización. Entre los propietarios predomina el nivel de escolaridad universitario, aunque no lo aprovechan.

En el ámbito legislativo, afectan al producto la Ley No. 182, Defensa del Consumidor, publicada en La Gaceta 213, el 14 de noviembre de 1994; la Ley 290, de Organización, Competencia y Procedimientos del Poder Ejecutivo y su Reglamento, publicada en La Gaceta 102, del 3 de Junio del año 1998, y el Decreto 71-98, publicado en La Gaceta 205-206 del 30 y 31 de Octubre del año 1998, que crea el Ministerio de Fomento, Industria y Comercio (MIFIC); y la Ley 382, Admisión Temporal para Perfeccionamiento Activo y facilitación de las Exportaciones, publicada en La Gaceta 70 del 16 de Abril.

\section{Oportunidades}

El calzado de cuero para mujer no presenta restricciones en los acuerdos suscritos entre Nicaragua y México. Con relación al SGP, permite a Nicaragua, exportar ciertos productos de origen nicaragüense con preferencias arancelarias a Estados Unidos de Norteamérica, Canadá, Unión Europea y Japón. Asimismo, la Unión Aduanera con Guatemala y El Salvador y el Mercado Común Centroamericano han facilitado la eliminación de la mayoría de obstáculos al comercio intraregional, han permitido un incremento comercial y se ha acordado una nueva política arancelaria con parámetros de $0 \%$ para materias primas y bienes de capital; 15\% para bienes finales, con dos franjas intermedias de 10\% para insumos y bienes de capital producidos en la región y 5\% para materias primas producidas en la región.

Aunque el 90\% de los artesanos saben calcular los costos de producción, no aplican sus conocimientos, porque se ven obligados a competir por precio; además, el dueño del taller realiza las labores de alistado y montado y no adiciona el costo de mano de obra al costo total del producto.

\section{Amenazas}

La demanda de este producto se ha reducido en los últimos 10 años, según informaron los dueños de taller, porque presenta poca calidad, ausencia de incentivos y fuerte y desleal competencia del extranjero y de productores nacionales con procesos industriales que manejan costos de producción más bajos como Calzado Manica, S. A. (Sandak), Rolter S.A. y La Chontal. La venta se realiza en el propio taller o en pequeñas tiendas y en los mercados 
populares de Masaya, de Managua, en los mercados de artesanías, en las ferias locales o patronales y en las ferias internacionales (centroamericanas).

A consecuencia de la cantidad y calidad inconstantes, sólo unos pocos productores exportan algo de su producción a Centro América. Los estilos y diseños no son variados por la falta de hormas actualizadas, cuyo precio es de 15-20 dólares cada una. Los estilos son mocasines, destalonados, semi cerrados, despuntados, sandalias, colegiales, de fiesta y de vestir, en colores natural, rojo, azul, negro, blanco, café y beige.

La mayoría de los talleres que producen calzado de cuero para mujer no han establecido estrategias definidas de promoción, precio, producto y producción, pero participan en ferias locales, nacionales y algunas veces logran exponer su producto en el extranjero. En cuanto a producción, se sigue el ritmo de los obreros, lo que no permite diseñar estrategias de control del nivel de producción. Con respecto al producto, además de no utilizar excelente materia prima, tampoco se definen niveles de calidad en la confección del calzado. Los artesanos venden su producto sin tomar en cuenta costos de producción, pues la estrategia de precio se basa en el precio de la competencia.

En este sector, el efecto de la inflación se manifiesta directamente en el precio del producto porque se oferta en moneda nacional. Además, el costo de los insumos es cada día mayor, aunque se compra en moneda local. No obstante, el artesano en su afán de mantener su clientela y sobrevivir a la crisis económica, compite por precio y trata de mantenerlo.

Las utilidades que genera la producción de calzado de cuero para mujer son relativamente bajas y que los intermediarios alcanzan utilidades un poco más altas que los artesanos. Sin embargo, estos son muy laboriosos y se desempeñan en otras actividades como estrategia de subsistencia: propietarios de taxis, producción agrícola, propietarios de comedirías, propietarios de pulperías, servicios de meseros, etc.

\section{Análisis de las fuerzas competitivas}

En este sector, la rivalidad entre los competidores es "alta": cada empresa compite en igualdad de condiciones; los artesanos compiten en un segmento de mercado de precio muy bajo y con productos indiferenciados dirigidos a la clase media-baja. La adquisición de materia prima de poca calidad y la ausencia de control de calidad en el acabado del producto impide que el calzado de cuero para mujer sea poco atractivo para segmentos de mayores ingresos.

Aunque el sector no presenta barreras de entrada significativas, no es atractivo para potenciales nuevos ingresantes nacionales y extranjeros, porque el mercado crece despacio y el nivel de utilidades es lento.

Los proveedores de materia prima tienen "alto" poder de negociación porque son pocos, están centralizados y los dueños de micro empresas no son clientes importantes. Por su parte, el poder de negociación de los compradores es "alto", porque pueden forzar a los vendedores a reducir el precio porque hay muchos productos sustitutos: calzado sintético 
importado, calzado de cuero usado, etc., que ofrecen variedad de estilo y precio accesible.

\section{Análisis del sistema de valor}

En el sector productor de calzado de cuero para mujer interactúan tres partes fundamentales: proveedores, productores y comercializadores. El sistema de valor da inicio con los proveedores, que suministran: cuero, vaqueta, tacón (madera y plástico) cambrillón, suela (expandida o cajuela-hule, pve y poliuretano), forro (tela y vinyl), pega, royal (fibra para reforzar la punta del zapato), hilo, hebillas, cinta reata, etiquetas y sellos.

El cuero y la vaqueta se compran a varias tenerías nacionales. Se utiliza el cuero liso y el cuero volteado en varios colores. Los otros insumos se compran a peleterías o a importadores directos. La mayoría de estos materiales se importan de Costa Rica y Guatemala. La maquinaria utilizada consiste en máquina de costura, horno de reactivación (cocina eléctrica), motor o lijadora, selladora (que pocos tienen), herramientas (cuchillo, martillo y tenazas), muebles de trabajo y hormas que pueden durar hasta 15 años y se adecuan al estilo moderno mediante aditivos. Todo el equipamiento se compra a proveedores nacionales e internacionales; su vida útil es de nueve años, pero la mayoría tiene más de 10 años en uso.

Los factores que inciden en la depresión del sector son la ausencia de visión empresarial, la crisis económica y la desorganización del sector. No obstante, el panorama está cambiando: un grupo de aproximadamente 40 artesanos del cuero están conformando una Asociación de Productores de la Industria del Calzado de Masaya (ASOPICMA).

Dentro del sistema de valor, el mayor peso recae en el taller, en los intermediarios locales y nacionales y en el gobierno central, que podría jugar un papel más beligerante y de apoyo al desarrollo del sector.

Los cuellos de botella se localizan en la tecnología aplicada, la maquinaria obsoleta utilizada, la confección inadecuada del producto e incapacidad técnica para producir hormas de calidad, esenciales para hacer calzado con nuevos estilos y medidas. Entre los problemas críticos del sector, se encuentran la deprimente comercialización, falta de estrategia de mercadeo, cultura empresarial que restringe la exportación del producto, débil participación de la INPYME y ausencia de políticas gubernamentales dirigidas al sector.

\section{La cultura empresarial en los talleres de calzado de cuero para mujer}

Con respecto al nivel cultural, sólo un 20\% de los entrevistados tiene nivel de Primaria; un $40 \%$ alcanza la Secundaria y el otro 40\%, universitario. En cuanto a la experiencia, de los propietarios de los talleres entrevistados, el 30\% tienen más de 22 años de haber iniciado; otro 30\%, más de 15 años y un 40\%, tiene más de siete años. Este dato evidencia que el sector está en manos de artesanos con la suficiente experiencia para manejarlo, desde el punto de vista práctico.

El $80 \%$ de los talleres son de tipo individual y el restante $20 \%$ es de tipo familiar. El bajo 
porcentaje de talleres familiares indica que se ha perdido la tradición familiar. El taller pequeño cuenta con 6 -19 trabajadores y representa el 75\%; el micro-taller cuenta con 1-5 trabajadores para un 15\%; y el taller mediano, de 20-30, con un 10\%. Los talleres están dentro de la casa de habitación del propietario, sin la infraestructura adecuada para las actividades del negocio.

En el aspecto financiero, el 50\% de los talleres trabajan combinando su propio capital con que obtienen de micro financieras y de la banca privada; el 40, trabaja con financiamiento externo y sólo el 10\% trabaja exclusivamente con su propio capital. La mayoría de los artesanos utilizan los préstamos para invertir en su taller y para gastos personales o familiares.

El $60 \%$ de los talleres producen un promedio mensual de 350 pares de calzado y el $40 \%$ restante, 800 pares. El 90\% de la producción se dirige a un segmento de la población mediabaja y el otro 10\%, al segmento media y alta. Ninguno de los talleres lleva registro contable en libros, pero sí el 80\% utiliza un cuaderno común donde anotar ingresos y egresos; el 20\% restante no hace ni eso.

\section{Una artesanía en crisis}

De todo lo anterior, se deduce que la pequeña industria del calzado de cuero está en crisis, pues está integrada por un gran número de talleres pequeños que compiten entre sí y con el calzado importado, con fuertes limitaciones financieras, tecnológicas y sociales. Además, la crisis económica ocasiona el cierre de muchos talleres, fuga de mano de obra especializada a países vecinos y cambio de actividad hacia los servicios.

Los artesanos del calzado de cuero para mujer no imputan la depreciación de la maquinaria para garantizar su reposición, quizá porque es obsoleta, lo que descapitaliza los talleres. Por lo tanto, no se aseguran la adquisición de una nueva ni el mantenimiento de la actual. Tampoco contabilizan los gastos administrativos y generales, obviando muchas veces el gasto de energía.

Otro factor limitante es la falta de hormas, de las que depende la buena calidad del calzado: una buena horma asegura que el zapato no dañe el pie. Los talleres no reponen sus hormas en el tiempo requerido; sólo las remodelan para adecuarlas a los estilos nuevos, pero eso significa diseñar calzado desfasado y de poca calidad.

La falta de mercadeo para la producción también afecta al sector. Se plantea un círculo vicioso en el que la falta de materiales y de capital de trabajo impide desarrollar la capacidad técnica para mejorar la producción, lo que incide en la capacidad de mercadeo por falta de calidad. Todo ello hace que los precios no sean competitivos, por lo que falta de mercado. En consecuencia, no hay mecanismos eficientes para la comercialización del calzado, que se realiza por los artesanos de manera empírica, sin técnicas adecuadas ni publicidad. 


\section{Recomendaciones}

Es urgente elevar la cultura empresarial de los artesanos del cuero calzado de Masaya, mediante seminarios, cursos, talleres y preparación continua, para que conozcan las ventajas de ser buen empresario. Se necesita establecer coordinaciones con el Banco Central de Nicaragua, para fijar políticas crediticias favorables para el sector. Los propietarios de talleres poseen bienes suficientes para optar a créditos preferentes para la adquisición de materia prima e insumos con el objetivo de bajar los costos de producción y mejorar la rentabilidad. El gobierno debe priorizar este sector, estableciendo alternativas económicas viables e informando acerca de las oportunidades que ofrecen los distintos convenios, acuerdos y tratados comerciales internacionales que Nicaragua suscribe.

Cuando el sector calzado se organice, podrá establecer estrategias en torno al mercadeo de su producto. También, a través de la asociación podrá influir en las relaciones comerciales con los proveedores, para obtener óptima materia prima a precio razonable. Se podrá negociar con distribuidores extranjeros el abastecimiento de hormas actualizadas y con precios competitivos. La asociación deberá luchar para que la Asamblea Nacional legisle respecto a la aplicación de aranceles a la importación de calzado.

Finalmente, de cara a las negociaciones y las oportunidades que nos ofrece el TLC con los Estados Unidos, es necesario revisar y priorizar los elementos que inciden en el desarrollo de este sector.

\section{Notas}

1 Sensación interior que resulta de una impresión material hecha en nuestros sentidos.

2 Sello Ecológico: una oportunidad para la MIPYME - Documento del MIFIC.

3 Ibídem. Pág. 10.

4 http://www.nodo50.org/espanica/cjust.html

5 Información suministrada por la Organización de las Naciones Unidades para el Desarrollo Industrial (ONUDI).

6 Información suministrada por la Organización de las Naciones Unidades para el Desarrollo Industrial (ONUDI).

\section{Referencias bibliográficas}

-ALABART PINO, Y., y PORTUONDO VÉLEZ, A. L., (1999). La cultura empresarial, una variable a considerar en la competitividad de las empresas, Folletos Gerenciales, Año 3, No. 3, marzo, La Habana, Cuba.

-BANCO INTERAMERICANO DE DESARROLLO (BID)-DEPARTAMENTO DE DESARROLLO SOSTENIBLE, (1999). La Comercialización de Artesanías, Experiencia de PROARTE, S.A. en Nicaragua, Conferencia de Servicios de Desarrollo Empresarial Río de Janeiro, del 3 al 5 de Marzo.

-BLOMSTER, (1999). Análisis del Potencial de Cluster de Hamacas. Masaya.

-COHEN, B. J., Introducción a la sociología, McGran Hill, México

-MARAÑÓN RODRÍGUEZ, E., BELLO RODRÍGUEZ, A., y BAUZÁ VÁZQUEZ, H., (s/f). Metodología para el diagnóstico y caracterización de la cultura organizacional en instituciones universitarias, Grupo de estudios de técnicas de dirección, Centro 
Universitario de las Tunas, Cuba.

-INSTITUTO NICARAGÜENSE DE APOYO A LA PEQUEÑA Y MEDIANA EMPRESA (INPYME), (s/f) Benmarking de Clusters de la PYME. Managua.

-INSTITUTO NICARAGÜENSE DE APOYO ALAPEQUEÑA Y MEDIANAEMPRESA (INPYME), (2003). La MIPYME en la Estrategia Nacional De Desarrollo, Resumen borrador de propuesta en consulta. Managua.

-HERNÁNDEZ MURGUÍA, J., (2001). Los esfuerzos de Nicaragua para regular el acceso a los recursos genéticos, Dirección General de Biodiversidad y Uso Sostenible de los Recursos Naturales del Ministerio del Ambiente y Recursos Naturales (MARENA, Managua.

-MARTÍNEZ VICIANA, J., (2003). La cadena de valor del comercio justo, Proyecto de Tesina, Universitat de Barcelona, Master de Comercio y Finanzas Internacionales, Valencia, España.

-MINISTERIO DE FOMENTO, INDUSTRIA Y COMERCIO (MIFIC), (2002). Diagnóstico situacional de la rama del cuero y calzado, Managua, Nicaragua

-Ministerio de Fomento, Industria y Comercio (MIFIC), (2003). Guía general para el inversionista 2002, Managua, Nicaragua.

-OTERO, D., (1994). Cultura Organizacional, Material de apoyo a la maestría en consultoría gerencial, Centro de Estudios de la Economía Cubana, CEEC, Universidad de La Habana, Ciudad de La Habana.

-RODAS TÉLLEZ, R., y ÁLVAREZ, M. D., (2000). Rol del diseño y la autogestión en el éxito de una PYME productora de hamacas, Estudio de caso durante el último semestre de 1999 y primer trimestre de 2000, Universidad Politécnica de Nicaragua, Managua, Nicaragua. -ROBBINS, S., (1991). Comportamiento Organizacional, Ed. Prentice-Hall, México -SHEIN, E. H., (1998). La cultura empresarial y el liderazgo, Ed. Plaza \& Janes, Barcelona, España. 